\title{
Differential effects of temperature on reactive oxygen/nitrogen species production in rat pachytene spermatocytes and round spermatids
}

\author{
José A Pino, Nelson Osses, Daniela Oyarzún, Jorge G Farías ${ }^{1}$, Ricardo D Moreno ${ }^{2}$ \\ and Juan G Reyes \\ Facultad de Ciencias, Instituto de Química, Pontificia Universidad Católica de Valparaíso, Valparaíso, Chile, \\ ${ }^{1}$ Departamento de Ingeniería Química, Facultad de Ingeniería, Ciencias y Administración, Universidad de La \\ Frontera, Temuco, Chile and ${ }^{2}$ Departamento de Fisiología, Facultad de Ciencias Biológicas, Pontificia Universidad \\ Católica de Chile, Santiago, Chile \\ Correspondence should be addressed to J G Reyes; Email: jreyes@ucv.cl
}

\begin{abstract}
Reactive oxygen species (ROS) and reactive nitrogen species (RNS) like superoxide and nitric oxide are produced by testis and spermatogenic cells in response to heat stress. However, the magnitude and mechanisms of this production in spermatogenic cells have not been described. In this work, we evaluated ROS/RNS production, its pharmacology, mitochondrial oxidative metabolism, membrane potential and antioxidant capacity at different temperatures in isolated rat pachytene spermatocytes and round spermatids. Our results showed an increment in ROS/RNS production by pachytene spermatocytes when increasing the temperature to $40{ }^{\circ} \mathrm{C}$. Instead, $\mathrm{ROS} / \mathrm{RNS}$ production by round spermatids did not change at temperatures higher than $33^{\circ} \mathrm{C}$. ROS/RNS production was sensitive to NADPH oxidase inhibitor diphenylene iodonium or the mitochondrial complex I inhibitor rotenone. No additive effects were observed for these two compounds. Our results suggest an important mitochondrial ROS/RNS production in spermatogenic cells. Oligomycin-insensitive oxygen consumption (uncoupled oxygen consumption) increased with temperature and was significantly larger in round spermatids than pachytene spermatocytes, indicating a likely round spermatid mitochondrial uncoupling at high temperatures. A similar conclusion can be reached by measuring the mitochondrial membrane potential using rhodamine 123 fluorescence in permeabilized cells or JC-1 fluorescence in intact cells. The antioxidant capacity was higher in round spermatids than pachytene spermatocytes at $40{ }^{\circ} \mathrm{C}$. Our results strongly suggest that at high temperatures $\left(40{ }^{\circ} \mathrm{C}\right)$ pachytene spermatocytes are more susceptible to oxidative stress, but round spermatids are more protected because of a temperature-induced mitochondrial uncoupling together with a larger antioxidant capacity. Reproduction (2013) 145 203-212
\end{abstract}

\section{Introduction}

The increase in testicular temperature observed in cryptorchidia and varicocele has been associated with an increase in testicular oxidative stress (Peltola et al. 1995). Reactive oxygen species/reactive nitrogen species (ROS/RNS) seem to be involved in the oxidative damage in these pathologies (Peltola et al. 1995, Lue et al. 2003, Romeo et al. 2003). In experimental models, heat stress of testis and testicular cells has been associated with spermatocyte apoptosis (Yin et al. 1997, Ikeda et al. 1999, Lue et al. 1999, Rockett et al. 2001, Somwaru et al. 2004) and ROS formation (Ikeda et al. 1999, Ishii et al. 2005), with a likely activation of the intrinsic pathway of apoptosis (Hikim et al. 2003; see Moreno et al. (2012) for a review). The mechanisms associated with this special temperature sensitivity of spermatocytes have not been fully studied, although a role of testis-specific heat shock proteins has been suggested (Nakai et al. 2000, Izu et al. 2004). The intracellular source and associated mechanisms of ROS formation leading to the high heat sensitivity of pachytene spermatocytes or, conversely, to the relative heat resistance of other germ cells have not been studied. In this context, not only ROS formation is important in understanding the differential cellular effects of heat on germ cells, but also the antioxidant capacity that would determine the final outcome of an ROS challenge in these cells (Bauche et al. 1994).

In this work, we studied the extent and sources of ROS/RNS production in response to different temperatures by isolated pachytene spermatocytes and round spermatids, complemented by a determination of mitochondrial metabolism and membrane potential. Our results show that an important ROS/RNS production in these cells was from the mitochondria, both at 33 and 
$40{ }^{\circ} \mathrm{C}$. Pachytene spermatocytes at high temperature $\left(40^{\circ} \mathrm{C}\right)$ had a higher ROS/RNS production compared with round spermatids. The lower ROS/RNS production induced by high temperature in round spermatids compared with pachytene spermatocytes was associated with a higher mitochondrial uncoupling, together with a larger antioxidant capacity in the latter cells. These properties of round spermatids can represent a protective mechanism from heat-induced oxidative stress in male reproductive cells. Furthermore, pachytene spermatocytes at high temperature $\left(40^{\circ} \mathrm{C}\right)$ were clearly subjected to a higher and differential oxidative stress compared with round spermatids, establishing a mechanistic basis for the high temperature sensitivity of the former cells.

\section{Results}

ROS or RNS production in round spermatids and pachytene spermatocytes incubated at different temperatures

When spermatogenic cells were incubated with $2^{\prime}, 7^{\prime}$ dichlorodihydrofluorescein diacetate $\left(\mathrm{H}_{2}\right.$ DCFDA; $2.5 \mu \mathrm{M})$ at $33^{\circ} \mathrm{C}$ in $\mathrm{KH}$-lactate media, an increase in the fluorescence signal was observed due to dichlorofluorescein (DCF) formation (Supplementary Figure 2, see section on supplementary data given at the end of this article). A possible photooxidation of the probe by the light source was discarded from experiments performed with the probe $(2.5 \mu \mathrm{M})$ in buffer (Supplementary Figure 2). Round spermatids and pachytene spermatocytes showed different kinetics of ROS/RNS formation ( $\left.k_{\mathrm{ROS} / \mathrm{RNS}}\right)$ at different temperatures (Fig. 1). In pachytene spermatocytes, when the incubation temperature was increased from 25 to $40{ }^{\circ} \mathrm{C}$, a progressive increase in ROS/RNS formation was observed, reaching $61 \%$ increase when the cells were taken from physiological temperature $\left(33^{\circ} \mathrm{C}\right)$ to a heat stress condition $\left(40^{\circ} \mathrm{C}\right.$ ) (Fig. 1). Instead, ROS/RNS production in round spermatids was not significantly different at the temperatures studied, showing a tendency to decrease at $40{ }^{\circ} \mathrm{C}$ (Fig. 1).

In order to compare the temperature dependence of the ROS/RNS formation process in spermatogenic cells, we determined the activation energy of ROS formation using an Arrhenius plot (Fig. 1B). We obtained a value of similar magnitude $(30 \pm 8 \mathrm{~kJ} / \mathrm{mol})$ to those obtained for ROS formation described in animal mitochondria (e.g. Abele et al. 2002) and also not very different from the Ea of oxygen consumption in these same cells (see below), suggesting a likely mitochondria-associated ROS/RNS production in pachytene spermatocytes. As expected from the data, an Arrhenius plot of $k_{\mathrm{ROS}}$ formation in round spermatids at different temperatures gave a positive slope (not shown), strongly suggesting that temperature was also activating an opposing process to ROS/RNS formation in these cells.
In order to identify the different sources of ROS/RNS formation in pachytene spermatocytes and round spermatids, both at basal temperature and under heat stress, a pharmacological approach was used with different inhibitors of systems that generate ROS/RNS in cells. Thus, we tested the NADPH oxidase (flavoprotein) inhibitor diphenylene iodonium (DPI); the nitric oxide synthase inhibitor $N^{G}$-methyl-L-arginine (LNMA); the mitochondrial complex I inhibitor rotenone (ROT); and the xanthine oxidase inhibitor allopurinol. Among
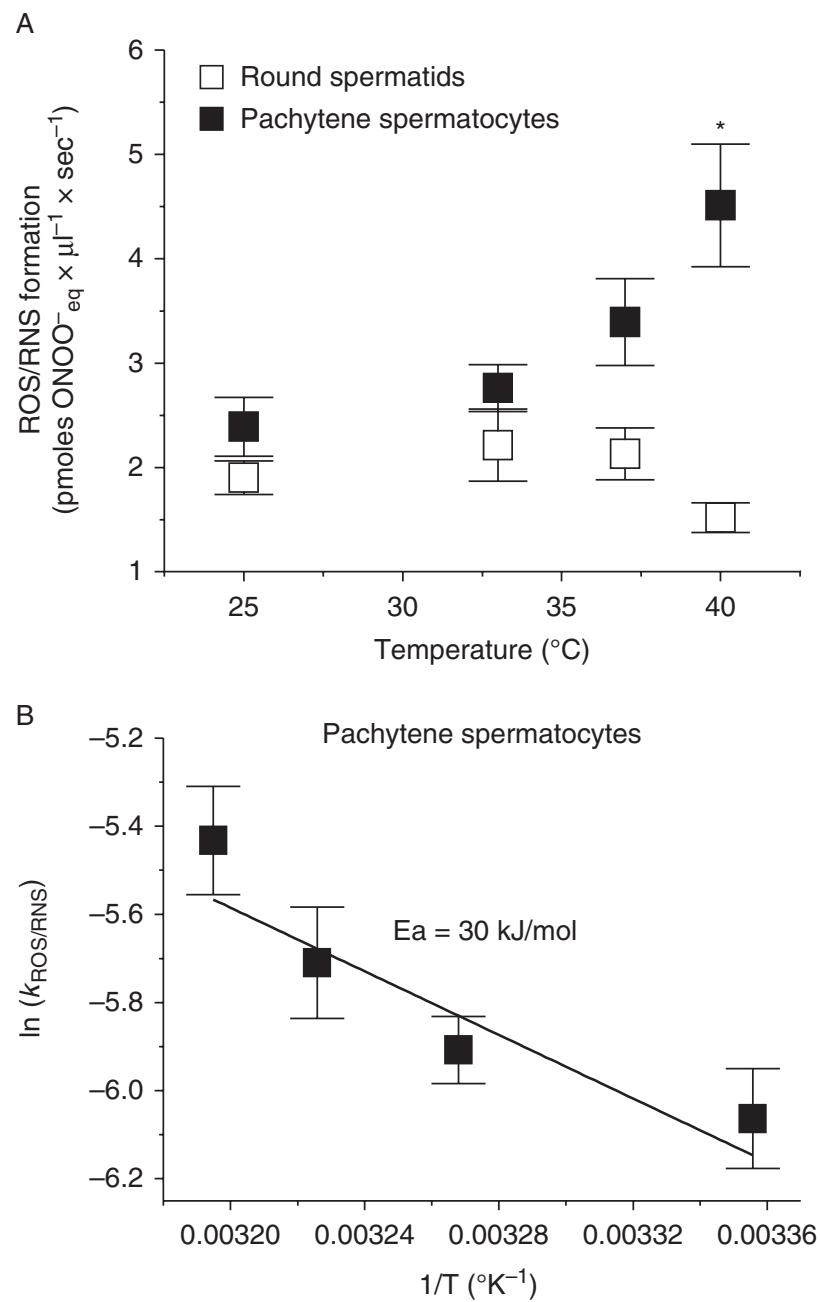

Figure 1 (A) ROS/RNS production rate in round spermatids and pachytene spermatocytes incubated at different temperatures. Each value represents the mean \pm S.E.M. of at least four different cell preparations. Round spermatids: $25^{\circ} \mathrm{C}(n=8), 33^{\circ} \mathrm{C}(n=6), 37^{\circ} \mathrm{C}$ $(n=8), 40^{\circ} \mathrm{C}(n=8)$. Pachytene spermatocytes: $25^{\circ} \mathrm{C}(n=5), 33^{\circ} \mathrm{C}$ $(n=6), 37^{\circ} \mathrm{C}(n=4), 40^{\circ} \mathrm{C}(n=5) .{ }^{*} P<0.05$, indicates significant differences in pachytene spermatocytes between 25 and $40{ }^{\circ} \mathrm{C}$, and between 33 and $40^{\circ} \mathrm{C}$. The fluorescence values were standardized for each cell type using the average cell volume and the cell density used in the assays. The statistical analysis was performed using ANOVA and post-hoc tests (Tukey). (B) Arrhenius plot of $k_{\text {ROS/RNS }}$ formation in pachytene spermatocytes at different temperatures. Each value represents the mean \pm S.E.M. of at least four different cell preparations. The number of measurements at each temperature is the same as in Figure $1 \mathrm{~A}$. 
these inhibitors, only DPI and ROT significantly inhibited the ROS/RNS production $(P<0.05)$, both at basal temperature $\left(33^{\circ} \mathrm{C}\right.$ ) and at $40{ }^{\circ} \mathrm{C}$ (Fig. 2) in both cell types studied. In pachytene spermatocytes, DPI decreased the $k_{\mathrm{ROS}}$ formation by 23 and $14 \%$ at
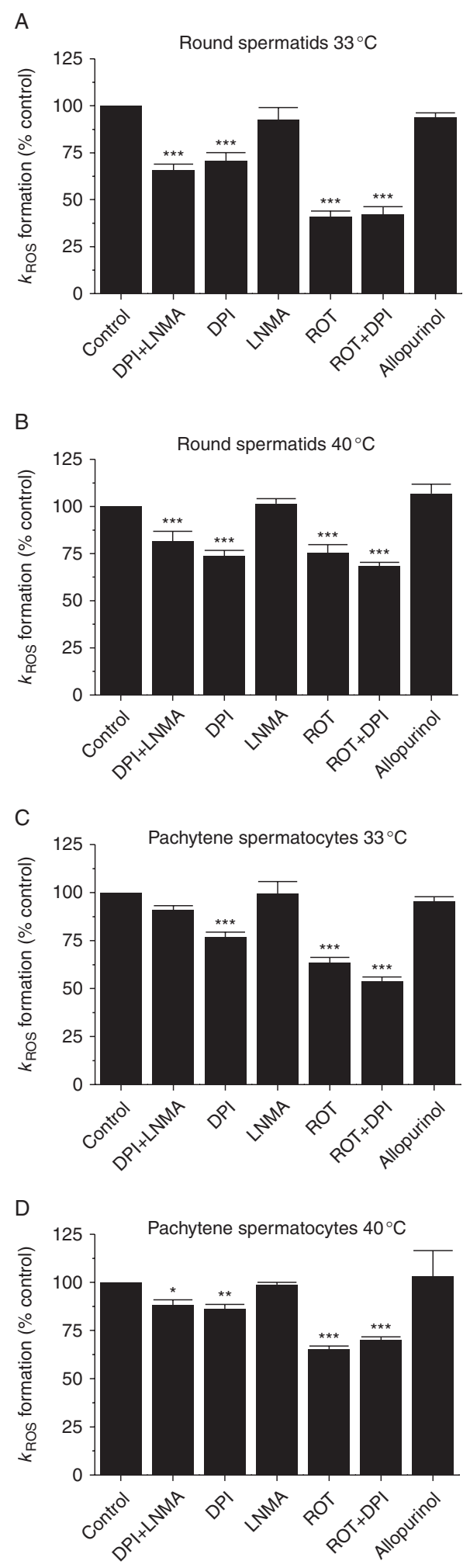

33 and $40{ }^{\circ} \mathrm{C}$ respectively. Additionally, in pachytene spermatocytes, ROT decreased the $k_{\text {ROS }}$ formation by 35 and $37 \%$ at 33 and $40{ }^{\circ} \mathrm{C}$ respectively (Fig. $2 \mathrm{~A}$ and B). In round spermatids, DPI decreased the $k_{\mathrm{ROS}}$ formation by 27 and $30 \%$ at 33 and $44{ }^{\circ} \mathrm{C}$ respectively (Fig. $2 \mathrm{C}$ and D). In these same cells, ROT decreased the $k_{\mathrm{ROS}}$ formation by 60 and $25 \%$ at 33 and $40{ }^{\circ} \mathrm{C}$ respectively (Fig. 2C and D). No additive effects were observed when DPI and ROT or, when DPI and LNMA were added to the cells, suggesting that DPI and ROT could share the same or related targets as inhibitors of ROS/RNS production.

Control experiments performed in order to check if some of the inhibitors used could affect mitochondrial oxygen consumption showed that DPI, LNMA or allopurinol did not affect oxygen consumption at $33{ }^{\circ} \mathrm{C}$ (Supplementary Figure 3, see section on supplementary data given at the end of this article). At this temperature, as expected, ROT and sodium cyanide $(\mathrm{NaCN})$ inhibited the oxygen consumption of round spermatids by 80 and $95 \%$ respectively. At $40{ }^{\circ} \mathrm{C}$, DPI showed a significant decrease in round spermatid oxygen consumption (24\%), indicating some cross inhibition of DPI in the mitochondrial electron chain (see also Hutchinson et al. (2007)). At $40{ }^{\circ} \mathrm{C}$, ROT and $\mathrm{NaCN}$ inhibited the round spermatid oxygen consumption by 92 and $97 \%$ respectively. Therefore, our results suggest that an important source of ROS/RNS production in spermatogenic cells at basal temperature and under a heat stress condition was their mitochondria.

In order to determine specifically the effect of temperature on mitochondrial ROS/RNS formation, we estimated the ROT-sensitive ROS/RNS formation as $k_{R^{\prime} O S / R N S_{\text {basal }}}-k_{\mathrm{ROS}_{\text {RNS }} \text { rotenone }}($ Fig. 3). The data of mitochondrial ROS/RNS formation at different temperatures gave a very similar relation to the ROS/RNS formation for the overall process (cf. Figs 1 and 3) both in pachytene spermatocytes and round spermatids, strongly suggesting a differential effect of temperature on pachytene spermatocyte and round spermatid mitochondrial

Figure 2 Rate of ROS/RNS formation in round spermatids and pachytene spermatocytes in the presence of inhibitors: nitric oxide synthase (LNMA, $10 \mu \mathrm{M}$ ), NADPH (flavin) oxidases (DPI, $20 \mu \mathrm{M}$ ), mitochondrial complex I (rotenone (ROT), $2 \mu \mathrm{M}$ ) and xanthine oxidase (allopurinol, $100 \mu \mathrm{M}$ ). The inhibitors were present $5 \mathrm{~min}$ before ROS/RNS measurements. Asterisks indicate significant differences with respect to controls without inhibitors $\left({ }^{*} P<0.05,{ }^{* *} P<0.01\right.$, $\left.{ }^{* * *} P<0.001\right)$. The statistical analysis was performed with ANOVA and post hoc tests (Tukey). (A) Round spermatids at $33^{\circ} \mathrm{C}$ : control $(n=23)$, $\mathrm{DPI}+\mathrm{LNMA}(n=6), \mathrm{DPI}(n=6), \mathrm{LNMA}(n=6)$, ROT $(n=6), \mathrm{ROT}+\mathrm{DPI}$ $(n=4)$, allopurinol $(n=4)$. (B) Round spermatids at $40^{\circ} \mathrm{C}$ : control $(n=15), \mathrm{DPI}+\mathrm{LNMA}(n=4), \mathrm{DPI}(n=5), \mathrm{LNMA}(n=6), \mathrm{ROT}(n=6)$, ROT+DPI $(n=4)$, allopurinol $(n=4)$. (C) Pachytene spermatocytes at $33^{\circ} \mathrm{C}$ : control $(n=20), \mathrm{DPI}+\mathrm{LNMA}(n=6), \mathrm{DPI}(n=6), \mathrm{LNMA}(n=6)$, ROT $(n=6)$, ROT $+\mathrm{DPI}(n=4)$, allopurinol $(n=4)$. (D) Pachytene spermatocytes at $40{ }^{\circ} \mathrm{C}$ : control $(n=15), \mathrm{DPI}+\operatorname{LNMA}(n=4)$, $\mathrm{DPI}(n=5), \mathrm{LNMA}(n=6)$, ROT $(n=6), \mathrm{ROT}+\mathrm{DPI}(n=4)$, allopurinol $(n=4)$. 


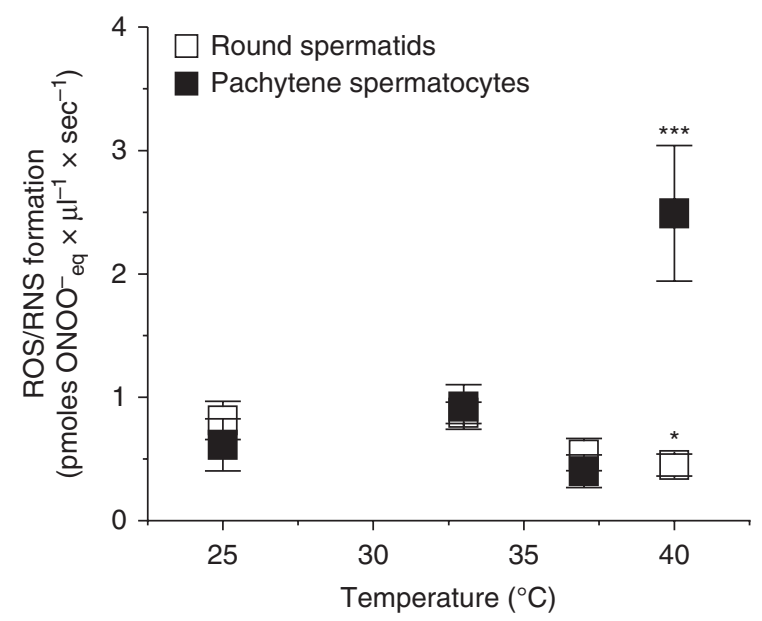

Figure 3 Mitochondrial (rotenone-dependent) ROS/RNS formation rate in round spermatids and pachytene spermatocytes incubated at different temperatures. Each value represents the mean \pm s.E.M. of at least four different experiments. ${ }^{*} P<0.05$ indicates significant differences in round spermatids between 33 and $40{ }^{\circ} \mathrm{C}$. ${ }^{* * *} P<0.001$ indicates significant differences in pachytene spermatocytes between $40{ }^{\circ} \mathrm{C}$ and all the other temperatures. The statistical analysis was performed using ANOVA and post hoc tests (Tukey). Round spermatids: $25^{\circ} \mathrm{C}(n=8), 33^{\circ} \mathrm{C}(n=6), 37^{\circ} \mathrm{C}(n=8), 40{ }^{\circ} \mathrm{C}(n=8)$. Pachytene spermatocytes: $25^{\circ} \mathrm{C}(n=5), 33^{\circ} \mathrm{C}(n=6), 37^{\circ} \mathrm{C}(n=4), 40{ }^{\circ} \mathrm{C}(n=5)$.

redox processes. These differences could be accounted for, either by a possible uncoupling of round spermatid mitochondrial oxidative phosphorylation at $40{ }^{\circ} \mathrm{C}$ (e.g. Mailloux \& Harper 2011) or a higher total antioxidant capacity of round spermatids at $40^{\circ} \mathrm{C}$.

\section{Heat stress induces mitochondrial uncoupling in round spermatids but not in pachytene spermatocytes}

Our results of ROS/RNS production in pachytene spermatocytes and round spermatids showed a differential effect of high temperature on this process in these two cell types. In order to elucidate the role of mitochondrial function in the differential effect of heat stress in these cells, we performed direct oxygen consumption measurements and also estimated the mitochondrial membrane potential in round spermatids and pachytene spermatocytes at $33{ }^{\circ} \mathrm{C}$ (physiological temperature) and $40^{\circ} \mathrm{C}$.

At the physiological temperature of rat testis, the basal oxygen consumption $\left(\mathrm{QO}_{2 \text { basal }}\right)$ of round spermatids in $\mathrm{KH}$-lactate media was $69 \%$ of the uncoupled oxygen consumption (maximal $\mathrm{QO}_{2}, \mathrm{QO}_{2 \max }$ ), showing that round spermatid mitochondria at this temperature still had an unused oxidative capacity of $30 \%$ of the $\mathrm{QO}_{2 \max }$ (Fig. 4A). Instead, pachytene spermatocytes showed a basal $\mathrm{QO}_{2}$ equivalent to $40 \% \mathrm{QO}_{2}$ max, indicating that pachytene spermatocyte mitochondria still had an unused oxidative capacity of $60 \%$ of the $\mathrm{QO}_{2 \max }$ (Fig. 4B). At $40{ }^{\circ} \mathrm{C}$, the basal $\mathrm{QO}_{2}$ in round spermatids reached almost the maximum oxygen consumption capacity (94\% of the $\mathrm{QO}_{2 \max }$ ), whereas in pachytene spermatocytes it was only $52 \%$ of the $\mathrm{QO}_{2 \max }$ (Fig. $4 \mathrm{~A}$ and $\mathrm{B})$. At both temperatures, the $\mathrm{QO}_{2}$ was almost completely blocked by antimycin A or KCN (inhibitors of mitochondrial electron transport), confirming that most cellular oxygen consumption in pachytene spermatocytes and round spermatids was a result of mitochondrial respiration. Pachytene spermatocyte and round spermatid basal $\mathrm{O}_{2}$ consumption gave Arrhenius activation energies of $53 \pm 18$ and $64 \pm 15 \mathrm{~kJ} / \mathrm{mol}$ respectively (Supplementary Figure 4, see section on supplementary data given at the end of this article).

As an estimation of uncoupled oxygen consumption (Fig. 5), we analyzed the oligomycin-insensitive oxygen
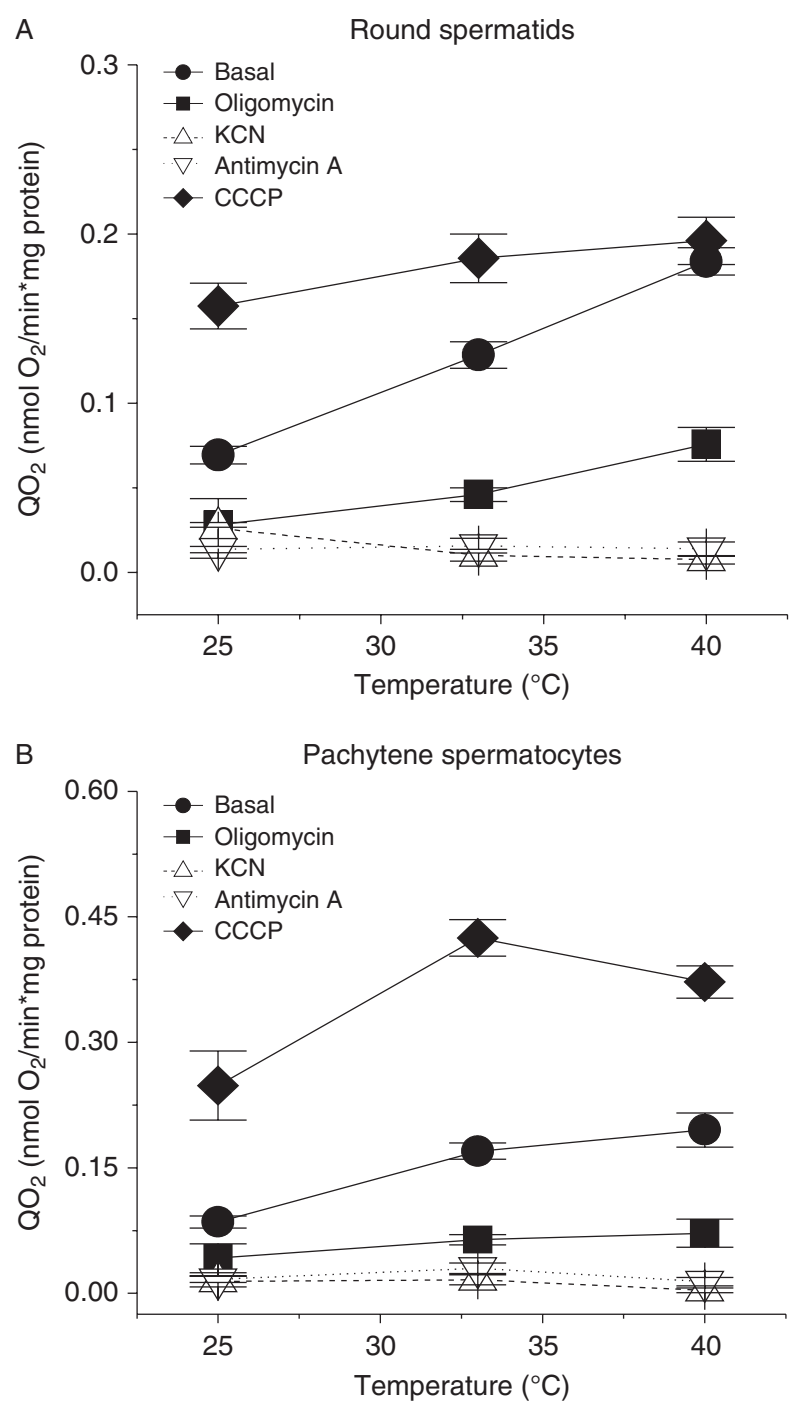

Figure 4 Rate of oxygen consumption $\left(\mathrm{QO}_{2}\right)$ in $(\mathrm{A})$ round spermatids and (B) pachytene spermatocytes incubated at different temperatures and in the absence (basal) and presence of different effectors of oxidative phosphorylation. Each value represents the mean \pm S.E.M. of at least four different experiments. Round spermatids: $25^{\circ} \mathrm{C}(n=6), 33^{\circ} \mathrm{C}$ $(n=5), 40^{\circ} \mathrm{C}(n=7)$. Pachytene spermatocytes: $25^{\circ} \mathrm{C}(n=3), 33^{\circ} \mathrm{C}$ $(n=3), 40^{\circ} \mathrm{C}(n=4)$. 


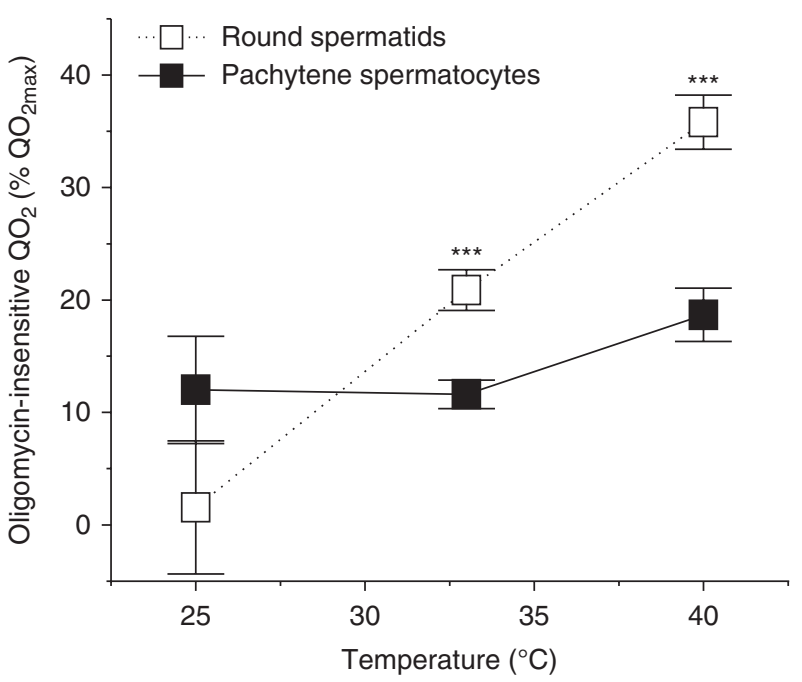

Figure 5 Oligomycin-insensitive (uncoupled) $\mathrm{QO}_{2}$ (expressed as percent $\mathrm{QO}_{2 \max }$ ) in round spermatids and pachytene spermatocytes incubated at different temperatures. $\mathrm{QO}_{2 \max }: \mathrm{QO}_{2}$ of cells incubated with CCCP $(2 \mu \mathrm{M}) .{ }^{* * *} P<0.0001$ indicates significant differences between round spermatids and pachytene spermatocytes (paired $t$-test). Round spermatids: $25^{\circ} \mathrm{C}(n=6), 33^{\circ} \mathrm{C}(n=5), 40{ }^{\circ} \mathrm{C}(n=7)$. Pachytene spermatocytes: $25^{\circ} \mathrm{C}(n=3), 33^{\circ} \mathrm{C}(n=3), 40{ }^{\circ} \mathrm{C}(n=4)$.

consumption in spermatogenic cells. At the physiological temperature $\left(33^{\circ} \mathrm{C}\right)$, the uncoupled $\mathrm{QO}_{2}$ in round spermatids was $80 \%$ higher than in pachytene spermatocytes. Under heat stress conditions $\left(40{ }^{\circ} \mathrm{C}\right)$, the uncoupled $\mathrm{QO}_{2}$ in round spermatids was $92 \%$ higher than in pachytene spermatocytes. These differences were statistically significant $(P<0.0001)$, confirming that round spermatids presented a partial uncoupling of oxidative phosphorylation with increasing temperatures.

Figure 6 shows the changes in the rhodamine 123 (R123) fluorescence ratio (an estimation of mitochondrial membrane potential) induced by heat stress $\left(40^{\circ} \mathrm{C}\right)$ in round spermatids and pachytene spermatocyte mitochondria. All the values were expressed using the R123 fluorescence ratios in the presence of carbonyl cyanide 3-chlorophenylhydrazone (CCCP; $0 \mathrm{mV}$ ) as a reference. In round spermatids, at $40{ }^{\circ} \mathrm{C}$, the $\mathrm{R} 123$ fluorescence ratios decreased significantly $(28 \%$ reduction; $P<0.05$ ), indicating a reduction in mitochondrial membrane potential (Fig. 6A), corroborating the notion that high temperature induced mitochondrial uncoupling in these cells. Instead, in pachytene spermatocytes, the R123 fluorescence ratios did not change significantly when the temperature was increased to $40^{\circ} \mathrm{C}$ (Fig. 6B). Similar to the R123

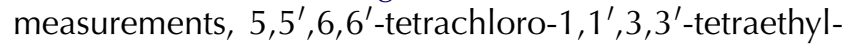
benzimidazolylcarbocyanine iodide (JC-1) measurements showed a significant decrease in round spermatid mitochondrial membrane potential exposed to heat stress conditions (Fig. 6C, 53\% reduction; $P<0.05)$ but not in the case of pachytene spermatocytes (Fig. 6D).
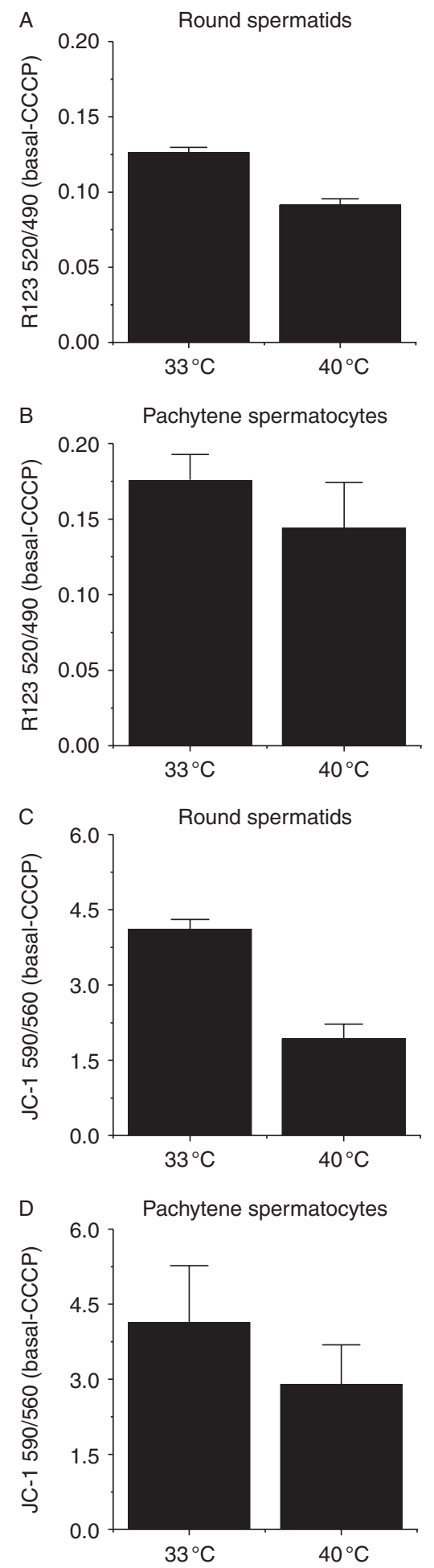

Figure 6 Mitochondrial membrane potential measurements. Rhodamine 123 (R123) fluorescence ratio $(520 / 490 \mathrm{~nm}$ excitation, emission $530 \mathrm{~nm}$ ) in (A) digitonin-permeabilized spermatids and (B) pachytene spermatocytes at 33 and $40{ }^{\circ} \mathrm{C}$. JC- 1 fluorescence ratio (590/560 nm emission, excitation $490 \mathrm{~nm}$ ) in (C) round spermatids and (D) pachytene spermatocytes at 33 and $40^{\circ} \mathrm{C}$. $(n=3$; mean \pm S.E.M. $)$ paired $t$-test, ${ }^{*} P<0.05 \mathrm{R} 123$ spermatids. ( $n=4$; mean \pm s.E.M.) paired $t$-test, $* P<0.05$ JC-1 spermatids. 
Thus, both $\mathrm{QO}_{2}$ measurements and mitochondrial membrane potential estimates agree that round spermatid but not pachytene spermatocyte mitochondria undergo partial uncoupling when exposed to $40{ }^{\circ} \mathrm{C}$.

\section{Cellular antioxidant capacity in round spermatids and pachytene spermatocytes incubated at different temperatures}

Relative round spermatid and pachytene spermatocyte antioxidant capacities were evaluated from the net ROS/RNS levels detected by $\mathrm{H}_{2}$ DCFDA under basal and oxidative stress conditions. Figure 7 shows that the $k_{\mathrm{ROS}}$ ratios ( $k_{\mathrm{ROS}}$ oxidative/ $k_{\mathrm{ROS}}$ basal; see Materials and Methods) determined with $\mathrm{H}_{2}$ DCFDA at $33{ }^{\circ} \mathrm{C}$ were not
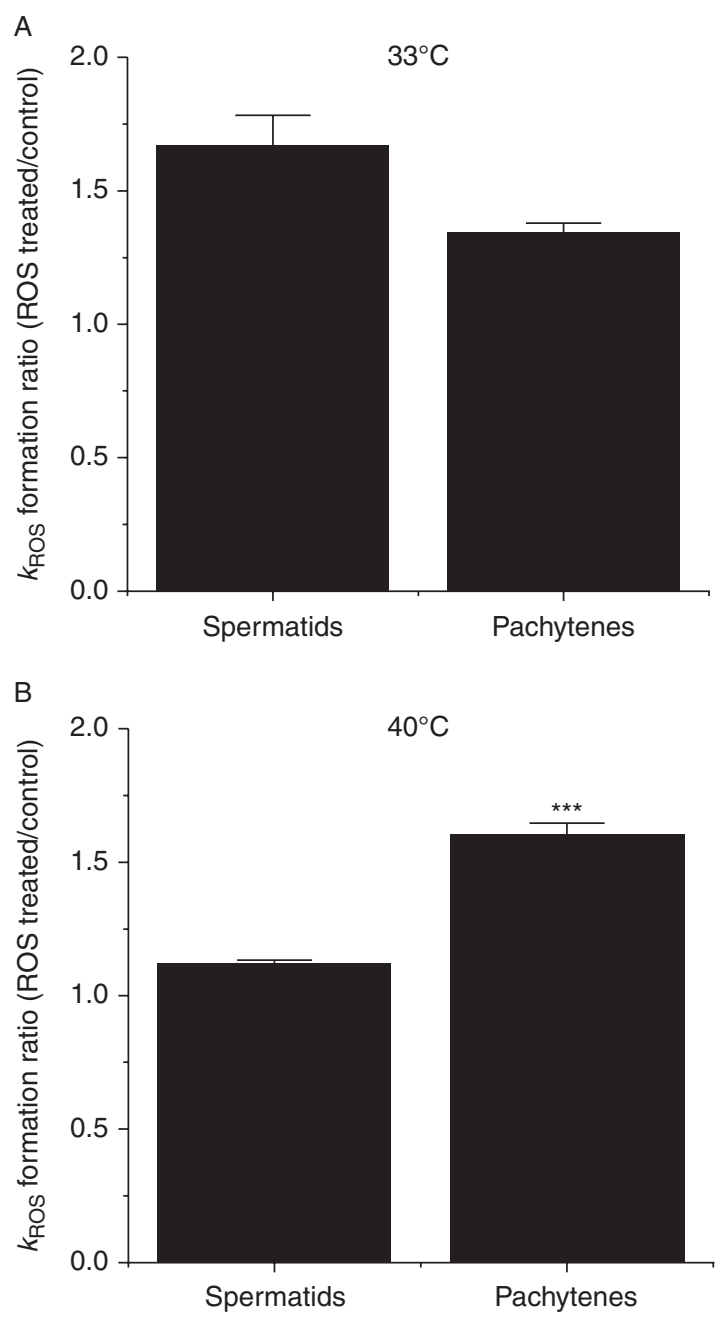

Figure 7 Cellular antioxidant capacity of round spermatids and pachytene spermatocytes estimated as the net ROS detection at $33^{\circ} \mathrm{C}$ (A) and $40^{\circ} \mathrm{C}(\mathrm{B})$ in the absence and presence of an oxidative challenge ( $k_{\mathrm{ROS}}$ formation ratio). The oxidative challenge was induced with $\mathrm{Fe}^{+3}$ $(197 \mu \mathrm{M})$ /ascorbate $(19.7 \mathrm{mM})$ that generates $\cdot \mathrm{O}_{2}{ }^{-}$and $\cdot \mathrm{OH}$ radicals. Each value represents the mean \pm s.E.M. of at least three different experiments. ${ }^{* * *} P<0.05$ indicates significant differences between round spermatids and pachytene spermatocytes (unpaired $t$-test). significantly different between round spermatids and pachytene spermatocytes. However, under heat stress $\left(40^{\circ} \mathrm{C}\right)$, round spermatids showed a significantly lower ROS production ratio (oxidative/basal) than pachytene spermatocytes $(30 \%$ less, $P<0.05)$ strongly suggesting an increased total antioxidant capacity (enzymatic and nonenzymatic) of round spermatids at the highest temperature tested $\left(40^{\circ} \mathrm{C}\right)$.

\section{Discussion}

Heat stress of testis and testicular cells has been associated with ROS formation (Ikeda et al. 1999, Ishii et al. 2005), spermatocyte apoptosis (Yin et al. 1997, Ikeda et al. 1999, Lue et al. 1999, Rockett et al. 2001, Hikim et al. 2003, Somwaru et al. 2004, Vera et al. 2005) and activation of the intrinsic pathway of apoptosis in these cells (Vera et al. 2005). This sensitivity of spermatocytes to heat stress appears to be associated with the heat shock transcription factor 1 (Nakai et al. 2000, Izu et al. 2004). However, the mechanisms that activate the spermatocyte intrinsic pathway of apoptosis and make spermatocytes differentially sensitive to heat stress, or, conversely, the mechanisms that make other spermatogenic cells resistant to heat stress, are still unknown. In this respect, Herrera et al. (2001) showed that increasing the incubation temperature of rat pachytene spermatocytes and round spermatids to $37-40{ }^{\circ} \mathrm{C}$ increased intracellular $\left[\mathrm{Ca}^{2+}\right]\left(\left[\mathrm{Ca}^{2+}\right]_{i}\right)$ to levels that effectively can modify signaling in these cells (e.g. Reyes et al. 2010). Also, the intracellular pH in these cells was found to decrease with increasing temperature. These changes occurred within $1 \mathrm{~min}$ of the increase in temperature and can be classified as early events in the response of these cells to heat stress. Interestingly, the same combination of changes in these cellular parameters (increase in $\left[\mathrm{Ca}^{2+}\right]_{i}$ and decrease in intracellular $\mathrm{pH}$ ) was associated with apoptotic cells in the testis (Lizama et al. 2007), strongly suggesting that high temperatures per se can set physiological conditions in spermatogenic cells that make them prone to other noxious or proapoptotic stimuli from Sertoli cells.

In this work, our results show that an increase in temperature increases ROS/RNS formation in pachytene spermatocytes but not in round spermatids. Pachytene spermatocyte and round spermatid basal $\mathrm{QO}_{2}$ gave Arrhenius activation energies (Ea) that did not differ from each other. Pachytene spermatocyte ROS/RNS production gave an Ea lower, but not significantly different, from $\mathrm{QO}_{2}$ Ea. These Ea values are comparable with those reported for oxidative processes in yeast mitochondria (Watson et al. 1975) or rat liver mitochondria (Smith 1978, Wander \& Berdanier 1985, Samartsev et al. 2003). In fact, the unexpected result in our experiments was the tendency for ROS/RNS production to decrease with higher temperature in round spermatids. Thus, in this work we studied the source of ROS/RNS production in 
pachytene spermatocytes and round spermatids at 33 and $40{ }^{\circ} \mathrm{C}$, and additionally, elucidated the mechanisms associated with the lack of increase in ROS/RNS production with increased temperatures in round spermatids.

As for the source of ROS/RNS production in pachytene spermatocytes and round spermatids, our results using a pharmacological approach suggested that mitochondria was an important source of ROS/RNS in these cells. Although we did not detect inhibition of $\mathrm{QO}_{2}$ by DPI at $33{ }^{\circ} \mathrm{C}$, the fact that at $40^{\circ} \mathrm{C}$ this compound partially inhibited $\mathrm{QO}_{2}$ in round spermatids (see also Hutchinson (2007)), together with the absence of additive effects of DPI plus ROT on ROS/RNS production, strongly suggests that DPI could be acting in the same target as ROT, and that an important source of ROS/RNS at 33 and $40{ }^{\circ} \mathrm{C}$ in pachytene spermatocytes and round spermatids was the mitochondria. As is evident in Fig. 2, there was an $\mathrm{H}_{2}$ DCFDA oxidation that was not inhibited by any of the redox processes inhibitors used in this work. This unaccounted for-DCF production was more pronounced at higher temperatures and could come from any redox process that produced hydrogen peroxide $\left(\mathrm{H}_{2} \mathrm{O}_{2}\right)$ in spermatogenic cells (e.g. cytochrome P450 and other oxidases). In fact, the results that ROT can inhibit $80-95 \%$ of oxygen consumption in the cells (most $\mathrm{QO}_{2}$ can be attributed to mitochondria) but it inhibited $25-30 \%$ of ROS/RNS formation at $40{ }^{\circ} \mathrm{C}$ strongly suggest that it is highly likely that $\mathrm{H}_{2}$ DCFDA could undergo ROS-independent oxidation in these cells. Nevertheless, and being the focus of our work, the ROT-sensitive ROS/ RNS production can be clearly attributed to mitochondria as judging from the effects of ROT on $\mathrm{QO}_{2}$ in these cells (Supplementary Figure 3). Our results and analysis of the $\mathrm{QO}_{2}$ of pachytene spermatocytes and round spermatids showed an increased oligomycininsensitive oxygen consumption (uncoupled respiration) in round spermatids at $40{ }^{\circ} \mathrm{C}(92 \%$ higher than pachytene spermatocytes) (Fig. 5), in agreement with a decreased ROS/RNS production at that temperature in these latter cells. The conclusion of a temperaturedependent uncoupling in round spermatids but not spermatocytes was also supported by the measurements of mitochondrial membrane potential. Thus, high temperature $\left(40^{\circ} \mathrm{C}\right)$ clearly induced a decrease in mitochondrial membrane potential in round spermatids but not in pachytene spermatocytes, consistent with heat-induced uncoupling in round spermatid mitochondria. As has been suggested in other works, a likely consequence of this mitochondrial uncoupling would be a lesser production of $\cdot \mathrm{O}_{2}^{-}$in the electron transport chain (Finkel \& Holbrook 2000, Mailloux \& Harper 2011). Thus, round spermatids appear 'protected' from heat stress in terms of mitochondrial ROS/RNS production compared with pachytene spermatocytes. Furthermore, our results strongly suggest that under heat stress conditions, round spermatids have a higher total antioxidant capacity than pachytene spermatocytes, contributing even further to the protection from ROS in these cells. Our results, showing an increased oxidative stress in pachytene spermatocytes at high temperature, provide a mechanism that, linked to other noxious stimuli in the heat-stressed testis (see also Herrera et al. (2001)) can help to explain the higher temperature sensitivity of pachytene spermatocytes. The heat stress-induced uncoupling of round spermatid mitochondria and its associated control of ROS/RNS production can certainly provide an explanation for their higher temperature resistance compared with spermatocytes in testis exposed to high temperature.

\section{Materials and Methods}

\section{Materials}

$\mathrm{H}_{2}$ DCFDA was obtained from Molecular Probes (Invitrogen). Sodium L-lactate, DMSO, allopurinol, ROT, DPI, LNMA, oligomycin, $\mathrm{CCCP}, \mathrm{NaCN}$, enzymes, salts and buffers were obtained from Sigma-Aldrich Chemical Co. Peroxynitrite $\left(\mathrm{ONOO}^{-}\right)$was synthesized in a quenched flow reactor according to Beckman et al. (1990), with some modifications. Peroxynitrite concentration was determined spectrophotometrically in $1 \mathrm{M} \mathrm{NaOH}\left(\varepsilon_{302} \mathrm{~nm}=1670 / \mathrm{M}\right.$ per $\left.\mathrm{cm}\right)$.

\section{Animals}

Sprague-Dawley adult rats were housed with free access to food and water, and under a $12 \mathrm{~h}$ light:12 h darkness photoperiod. The animals were killed by cervical dislocation after being narcotized with $\mathrm{CO}_{2}$ for $45 \mathrm{~s}$. Animal procedures were performed in agreement with the Principles of Laboratory Animal Care, advocated by the National Society of Medical Research, and the Guide for the Care and Use of Laboratory Animal (Institute of Animal Laboratory Resources, 1996). All animal protocols were endorsed by the Comision Nacional de Investigacion en Ciencia y Tecnologia, Chile.

\section{Preparation of rat spermatogenic cells}

Spermatogenic cell populations were prepared from adult rat testicles (50-70 days old) using velocity sedimentation separation in a 2-4\% BSA gradient, as described by Romrell et al. (1976). Pachytene spermatocyte $(85 \pm 5 \%$ purity) and round spermatid fractions ( $92 \pm 4 \%$ purity) were identified both by their size and by the typical aspect of their nucleus stained with Hoechst 33342 (Reyes et al. 1997).

\section{ROS/RNS production measurements}

Rat spermatogenic cells were suspended in $\mathrm{KH}$ buffer containing (in $\mathrm{mM}$ ) $144 \mathrm{NaCl}, 4.2 \mathrm{KCl}, 1.6 \mathrm{MgCl}_{2}, 1.6$ $\mathrm{KH}_{2} \mathrm{PO}_{4}, 10$ HEPES, pH 7.4, supplemented with $0.5 \mathrm{CaCl}_{2}$ and 10 lactate to a final concentration of $3 \times 10^{5}$ cell $/ \mathrm{ml}$. Cells were preincubated for $5 \mathrm{~min}$ at different temperatures (25$\left.40^{\circ} \mathrm{C}\right)$, and then $\mathrm{H}_{2}$ DCFDA $(2.5 \mu \mathrm{M})$ was added to the cell 
suspension. Fluorescence measurements of DCF (the product of $\mathrm{H}_{2}$ DCFDA oxidation) (excitation $495 \mathrm{~nm}$, emission $529 \mathrm{~nm}$ ) were made at 4-s intervals for $15 \mathrm{~min}$ in a Fluoromax-2 fluorometer (Jobin Yvon-Spex, Edison, NJ, USA).

As described by Crow (1997), in vitro addition of peroxynitrite $(80 \mu \mathrm{M})$ oxidized the probe $\mathrm{H}_{2}$ DCFDA $(2.5 \mu \mathrm{M})$ at $33{ }^{\circ} \mathrm{C}$ and $\mathrm{pH}$ 7.4. Neither superoxide $\left(1.3 \mu \mathrm{M} \cdot \mathrm{O}_{2}^{-} / \mathrm{min}\right)$ nor $\mathrm{H}_{2} \mathrm{O}_{2}(100 \mu \mathrm{M})$ could oxidize the probe in the same conditions (Supplementary Figure 1A, see section on supplementary data given at the end of this article). In the presence of peroxidase activity or cells, $\mathrm{H}_{2} \mathrm{O}_{2}$ was able to oxidize $\mathrm{H}_{2}$ DCFDA (Supplementary Figure $1 \mathrm{~B}$ ). Hence, $\mathrm{H}_{2}$ DCFDA oxidation reflects intracellular RNS or ROS formation in cells.

Standardization of the probe oxidation was made with peroxynitrite at different concentrations in the same conditions as the samples. Background signals correspond to the cells $\left(3 \times 10^{5}\right.$ cells $\left./ \mathrm{ml}\right)$ suspended in $\mathrm{KH}$ buffer without the probe. The results were expressed as DCF fluorescence minus the background and normalized per cell volume $(\mu \mathrm{l})$ using the average diameter of round spermatids $(11 \mu \mathrm{m})$ and pachytene spermatocytes $(16 \mu \mathrm{m})$. When the results were expressed in terms of $\mathrm{ONOO}^{-}$formed, the fluorescence signal of DCF was converted to nanomoles of $\mathrm{ONOO}^{-}$equivalents $\left(\mathrm{ONOO}^{-}{ }_{\text {eq }}\right)$ by performing a standard curve of DCF fluorescence vs $\mathrm{ONOO}^{-}$concentration.

\section{ROS/RNS formation data analysis}

The ROS/RNS formation rate constants correspond to the slope of the line obtained by linearization of the time course DCF fluorescence (expressed as nanomoles of $\mathrm{ONOO}^{-}$ equivalents) and described by the following equation:

$\ln (\mathrm{Ct} / \mathrm{Co})=k_{\text {ROS/RNS formation }} \times t$

Where, $\mathrm{Ct}$ are the nanomoles of $\mathrm{ONOO}^{-}$equivalents at time $t(\mathrm{~s}), \mathrm{Co}$ are the nanomoles of $\mathrm{ONOO}^{-}$equivalents

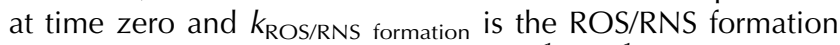
rate constant (nmol of $\mathrm{ONOO}^{-}{ }_{\text {eq }} \times \mu \mathrm{I}^{-1} \times \mathrm{s}^{-1}$ ).

\section{Oxygen consumption measurements}

Oxygen consumption $\left(\mathrm{QO}_{2}\right)$ measurements were performed using a Clark-type $\mathrm{O}_{2}$ sensing electrode (YSI, Yellow Springs, $\mathrm{OH}, \mathrm{USA})$ in a sealed glass chamber $(1.1 \mathrm{ml})$ surrounded by a water jacket kept at different temperatures $\left(25-40{ }^{\circ} \mathrm{C}\right)$. Isolated spermatogenic cells were preincubated for $1 \mathrm{~min}$ in $\mathrm{KH}$ buffer at the specified temperatures before being transferred to the $\mathrm{QO}_{2}$ chamber. $\mathrm{QO}_{2}$ values were obtained from the slope of the $\mathrm{O}_{2}$ tension vs time curve between 0.5 and $2.0 \mathrm{~min}$ after each experimental addition.

\section{R123 and JC-1 mitochondrial membrane potential measurements}

The mitochondrial membrane potential changes were estimated using the lipophilic cationic probe R123. Spermatogenic cells in suspension ( 2 million cells $/ \mathrm{ml}$ ) were permeabilized with 20 and $25 \mu \mathrm{g} / \mathrm{ml}$ digitonin (spermatids and pachytene spermatocytes respectively) (see also Reyes \& Benos (1984)) in a high- $\mathrm{K}^{+}$medium $\left(\mathrm{HK}^{+}\right)$containing $(\mathrm{mM}) 140 \mathrm{KCl}, 5$ $\mathrm{KH}_{2} \mathrm{PO}_{4}, 1.6 \mathrm{MgCl}_{2}, 10$ HEPES, 1 EGTA, pH 7.4 and exposed to $300 \mathrm{nM} \mathrm{R} 123$ for $5 \mathrm{~min}$. Subsequently, the excitation spectra $(450-520 \mathrm{~nm})$ at an emission wavelength of $530 \mathrm{~nm}$ were taken at the different temperatures tested. R123 undergoes quenching when accumulated by a negative mitochondrial inner membrane potential, with also a red shift in the excitation spectrum (Emaus et al. 1986). The excitation ratio 520/490 with an emission wavelength of $530 \mathrm{~nm}$ reflects the mitochondrial membrane potential and would decrease upon depolarization of the membrane potential (Emaus et al. 1986, Scaduto \& Grotyohann 1999).

JC-1 can also be used to estimate the mitochondrial membrane potential changes. Spermatogenic cells in suspension with $\mathrm{KH}$ buffer supplemented with $0.5 \mathrm{mM} \mathrm{CaCl}_{2}$ and $10 \mathrm{mM}$ lactate (1 million cells/ml) were incubated with JC-1 (200 nM) for $15 \mathrm{~min}$. JC-1 dye exhibits potential-dependent accumulation in mitochondria and aggregates formation, indicated by a fluorescence emission shift maxima from green $(\sim 529 \mathrm{~nm})$ to red $(\sim 590 \mathrm{~nm})$. The emission ratio 590/560 with an excitation wavelength of $514 \mathrm{~nm}$ reflects the mitochondrial membrane potential and would decrease upon depolarization of the membrane potential (e.g. Smiley et al. 1991).

\section{Cellular antioxidant capacity of spermatogenic cells}

The antioxidant capacity of the spermatogenic cells was studied by exposing the cells $\left(3 \times 10^{5}\right.$ cells $/ \mathrm{ml}$ in $\mathrm{KH}$ buffer supplemented with $0.5 \mathrm{mM} \mathrm{CaCl}_{2}$ and $10 \mathrm{mM}$ lactate) to an ROS-generating system simultaneously with DCF measurements (see above) for $10 \mathrm{~min}$ at 33 and $40{ }^{\circ} \mathrm{C}$. The ROSgenerating system (oxidative condition) was composed of $\mathrm{FeCl}_{3}(197 \mu \mathrm{M})$ and ascorbate $19.7 \mathrm{mM}$, producing $\cdot \mathrm{O}_{2}^{-}$, $\mathrm{H}_{2} \mathrm{O}_{2}$ and $\cdot \mathrm{OH}$ (e.g. Davies et al. 2007). With a constant ROS challenge, the net ROS concentration estimated by $\mathrm{H}_{2}$ DCFDA would depend on the total antioxidant capacity of the cells. The results are expressed as the ratio between the $k_{\mathrm{ROS}}$ under oxidative condition over the $k_{\mathrm{ROS}}$ under basal condition $\left(k_{\mathrm{ROS}}\right.$ oxidative $/ k_{\mathrm{ROS}}$ basal). Thus, the $k_{\mathrm{ROS}}$ ratio would be closer to 1 for higher cell antioxidant capacities, i.e. cells that could inactivate the ROS generated under an oxidative condition.

\section{Statistical analysis}

The data were analyzed using ANOVA followed by Tukey's post hoc test. In some cases, paired $t$-tests were used as indicated (GraphPad Prism, GraphPad Software, Inc., La Jolla, CA, USA). Kinetic data analysis was performed with the ORIGIN Software package 6.0 (OriginLab, Northampton, MA, USA).

\section{Supplementary data}

This is linked to the online version of the paper at http://dx.doi. org/10.1530/REP-12-0330. 


\section{Declaration of interest}

The authors declare that there is no conflict of interest that could be perceived as prejudicing the impartiality of the research reported.

\section{Funding}

Funding was provided by CONICYT doctoral fellowship to J A Pino (grant numbers 21080629 and 24100103), Fondo Nacional de Ciencia y Tecnología grant (grant number 1110267) and a PUCV-VRIEA grant to J G Reyes and Fondo Nacional de Ciencia y Tecnología grant (grant number 1110778) to R D Moreno.

\section{Acknowledgements}

Interesting and stimulating conversations with Drs Gloria Celedon and Gustavo Gonzalez on the subject of this article are gratefully acknowledged.

\section{References}

Abele D, Heise K, Pörtner HO \& Puntarulo S 2002 Temperaturedependence of mitochondrial function and production of reactive oxygen species in the intertidal mud clam Mya arenaria. Journal of Experimental Biology 205 1831-1841.

Bauche F, Fouchard MH \& Jegou B 1994 Antioxidant system in rat testicular cells. FEBS Letters 349 392-396. (doi:10.1016/0014-5793(94)00709-8)

Beckman JS, Beckman TW, Chen J, Marshall PA \& Freeman BA 1990 Apparent hydroxyl radical production by peroxynitrite: implications for endotelial injury from nitric oxide and superoxide. PNAS 87 1620-1624. (doi:10.1073/pnas.87.4.1620)

Crow JP 1997 Dichlorodihydrofluorescein and dihydrorhodamine 123 are sensitive indicators of peroxynitrite in vitro: implications for intracellular measurement of reactive nitrogen and oxygen species. Nitric Oxide 1 145-157. (doi:10.1006/niox.1996.0113)

Davies SS, Amarnath V, Brame CJ, Boutaud O \& Roberts LJ II 2007 Measurement of chronic oxidative and inflammatory stress by quantification of isoketal/levuglandin $\gamma$-ketoaldehyde protein adducts using liquid chromatography tandem mass spectrometry. Nature Protocols 2 2079-2091. (doi:10.1038/nprot.2007.298)

Emaus RK, Grunwald R \& Lemasters JJ 1986 Rhodamine 123 as a probe of transmembrane potential in isolated rat-liver mitochondria: spectral and metabolic properties. Biochemica et Biophysica Acta 850 436-448. (doi:10.1016/0005-2728(86)90112-X)

Finkel T \& Holbrook NJ 2000 Oxidants, oxidative stress and the biology of ageing. Nature 408 239-247. (doi:10.1038/35041687)

Herrera E, Salas K, Lagos N, Benos DJ \& Reyes JG 2001 Temperature dependence of intracellular $\mathrm{Ca}^{2+}$ homeostasis in rat meiotic and postmeiotic spermatogenic cells. Reproduction 122 545-551. (doi:10. 1530/rep.0.1220545)

Hikim APS, Lue Y, Yamamoto CM, Vera Y, Rodriguez S, Yen PH, Soeng K, Wang C \& Swerdloff RS 2003 Key apoptotic pathways for heat-induced programmed germ cell death in the testis. Endocrinology 144 3167-3175. (doi:10.1210/en.2003-0175)

Hutchinson DS, Csikasz RI, Yamamoto DL, Shabalina IG, Wikström P, Wilcke M \& Bengtsson T 2007 Diphenylene iodonium stimulates glucose uptake in skeletal muscle cells through mitochondrial complex I inhibition and activation of AMP-activated protein kinase. Cell Signalling 19 1610-1620. (doi:10.1016/j.cellsig.2007.02.006)

Ikeda M, Kodama H, Fukuda J, Shimizu Y, Murata M, Kumagai J \& Tanaka T 1999 Role of radical oxygen species in rat testicular germ cell apoptosis induced by heat stress. Biology of Reproduction 61 393-399. (doi:10. 1095/biolreprod61.2.393)
Ishii T, Matsuki S, luchi Y, Okada F, Toyosaki S, Tomita Y, Ikeda Y \& Fujii J 2005 Accelerated impairment of spermatogenic cells in SOD1-knockout mice under heat stress. Free Radical Research 39 697-705. (doi:10.1080/ 10715760500130517)

Izu H, Inouye S, Fujimoto M, Shiraishi K, Naito K \& Nakai A 2004 Heat shock transcription factor 1 is involved in quality-control mechanisms in male germ cells. Biology of Reproduction 70 18-24. (doi:10.1095/ biolreprod.103.020065)

Lizama C, Alfaro I, Reyes JG \& Moreno RD 2007 Up-regulation of CD95 (Apo-1/Fas) is associated with spermatocyte apoptosis during the first round of spermatogenesis in the rat. Apoptosis 12 499-512. (doi:10. 1007/s10495-006-0012-1)

Lue Y, Hikim APS, Swerdloff RS, Im P, Taing KS, Bui T, Leung A \& Wang C 1999 Single exposure to heat induces stage-specific germ cell apoptosis in rats: role of intratesticular testosterone on stage specificity. Endocrinology 140 1709-1717. (doi:10.1210/en.140.4.1709)

Lue Y, Hikim APS, Wang C, Leung A \& Swerdloff RS 2003 Functional role of inducible nitric oxide synthase in the induction of male germ cell apoptosis, regulation of sperm number, and determination of testes size: evidence from null mutant mice. Endocrinology 144 3092-3100. (doi:10.1210/en.2002-0142)

Mailloux RJ \& Harper ME 2011 Uncoupling proteins and the control of mitochondrial reactive oxygen species production. Free Radical Biology \& Medicine 51 1106-1115. (doi:10.1016/j.freeradbiomed. 2011.06.022)

Moreno RD, Reyes JG, Farías JG, Parada-Bustamante A, Aguirre V, Zepeda AB, Figuero C \& Pino JA 2012 Spermatogenesis at the extreme: oxidative stress as a converging mechanism of testicular damage due to pathological and environmental exposure. In Testis: Anatomy, Physiology and Pathology, pp 1-24. Eds Y Nemoto\& N Inaba. New York, USA: Nova Publishers.

Nakai A, Suzuki M \& Tanabe M 2000 Arrest of spermatogenesis in mice expressing an active heat shock transcription factor 1. EMBO Journal 9 1545-1554. (doi:10.1093/emboj/19.7.1545)

Peltola V, Huhtaniemi I \& Ahotupa M 1995 Abdominal position of the rat testis is associated with high level of lipid peroxidation. Biology of Reproduction 53 1146-1150. (doi:10.1095/biolreprod53.5.1146)

Reyes J \& Benos DJ 1984 Changes in interfacial potentials induced by carbonylcyanide phenylhydrazone uncouplers: possible role in inhibition of mitochondrial oxygen consumption and other transport processes. Membrane Biochemistry 5 243-268. (doi:10.3109/09687688409150281)

Reyes JG, Diaz A, Osses N, Opazo C \& Benos DJ 1997 On stage single cell identification of rat spermatogenic cells. Biology of the Cell 89 53-66. (doi:10.1016/S0248-4900(99)80081-1)

Reyes JG, Osses N, Knox M, Darszon A \& Trevino CL 2010 Glucose and lactate regulate maitotoxin-activated $\mathrm{Ca}^{2+}$ entry in spermatogenic cells: the role of intracellular $\left[\mathrm{Ca}^{2+}\right]$. FEBS Letters 584 3111-3115. (doi:10. 1016/j.febslet.2010.05.051)

Rockett JC, Mapp FL, Garges JB, Luft JC, Mori C \& Dix DJ 2001 Effects of hyperthermia on spermatogenesis, apoptosis, gene expression, and fertility in adult male mice. Biology of Reproduction 65 229-239. (doi:10.1095/biolreprod65.1.229)

Romeo C, Ientile R, Impellizzeri P, Turiaco N, Teletta M, Antonuccio P, Basile M \& Gentile C 2003 Preliminary report on nitric oxide-mediated oxidative damage in adolescent varicocele. Human Reproduction 18 26-29. (doi:10.1093/humrep/deg004)

Romrell LJ, Bellve AR \& Fawcett DW 1976 Separation of mouse spermatogenic cells by sedimentation velocity. A morphological characterization. Developmental Biology 49 119-131. (doi:10.1016/ 0012-1606(76)90262-1)

Samartsev VN, Chezganova SA, Polishchuk LS, Paydyganov AP, Vidyakina OV \& Zeldi IP 2003 Temperature dependence of rat liver mitochondrial respiration with uncoupling of oxidative phosphorylation by fatty acids. Influence of inorganic phosphate. Biochemistry 68 618-626.

Scaduto RC Jr \& Grotyohann LW 1999 Measurement of mitochondrial membrane potential using fluorescent rhodamine derivatives. Biophysical Journal 76 469-477. (doi:10.1016/S0006-3495(99)77214-0)

Smiley ST, Reers M, Mottola-Hartshorn C, Lin M, Chen A, Smith TW, Steele GD Jr \& Chen LB 1991 Intracellular heterogeneity in mitochondrial membrane potentials revealed by a J-aggregate-forming lipophilic cation JC-1. PNAS 88 3671-3675. (doi:10.1073/pnas.88.9.3671) 
Smith CL 1978 The temperature dependence of state IV respiration, the calcium uptake system, and the activity of the calcium ionophore A23187 in mitochondria from endo- and ectothermic animals. Comparative Biochemistry and Physiology 59B 231-237.

Somwaru L, Li S, Doglio L, Goldberg E \& Zirkin BR 2004 Heat-induced apoptosis of mouse meiotic cells is suppressed by ectopic expression of testis-specific calpastatin. Journal of Andrology 25 506-513.

Vera Y, Rodriguez S, Castanares M, Lue Y, Atienza V, Wang C, Swerdloff RS \& Hikim APS 2005 Functional role of caspases in heat-induced testicular germ cell apoptosis. Biology of Reproduction 72 516-522. (doi:10.1095/ biolreprod.104.034520)

Wander RC \& Berdanier CD 1985 Effects of dietary carbohydrate on mitochondrial composition and function in two strains of rats. Journal of Nutrition 115 190-199.
Watson K, Bertoli E \& Griffiths DE 1975 Phase transitions in yeast mitochondrial membranes. The effect of temperature on the energies of activation of the respiratory enzymes of Saccharomyces cerevisiae. Biochemical Journal 146 401-407.

Yin Y, Hawkins KL, DeWolf WC \& Morgentaler A 1997 Heat stress causes testicular germ cell apoptosis in adult mice. Journal of Andrology $\mathbf{1 8}$ 159-165.

Received 25 August 2012

First decision 28 September 2012

Accepted 13 December 2012 